\title{
Effects of Shape and Packing Density of Powder Particles on the Fluidity of Cement Pastes with Limestone Powder
}

\author{
Etsuo Sakai $^{1}$, Keisuke Masuda ${ }^{1}$, Yasuo Kakinuma ${ }^{1}$ and Yutaka Aikawa ${ }^{2}$
}

Received 9 June 2009, accepted 25 September 2009

\begin{abstract}
The fluidity and flow mechanism of suspensions containing low-heat Portland cement, limestone powders with different characteristics, and a polycarboxylate-based superplasticizer have been studied. Limestone powders with six different degrees of grinding were prepared using a ball mill and a jet mill. The circularity of the limestone powder particles was determined by analyzing scanning electron microscope (SEM) photographs of the particles using an image analyzer and the point counting method. A computer program for determining the packing fraction of powder particles directly from the particle size distribution was written and the packing fraction was calculated. It was made clear quantitatively that the packing fraction and circularity of limestone powder particles significantly affected the fluidity of the suspensions. The addition of finely ground limestone powders prepared by jet mill increased the fluidity of suspensions. The fluidity of low-heat Portland cement paste with finely ground limestone powders prepared by jet mill at a water-to-powder ratio of 0.225 is as same as the fluidity of low-heat Portland cement paste at a water-to-powder ratio of 0.30 . The fluidity of a suspension could be approximated with accuracy using the packing fraction and the circularity of powders. Particles with a circular shape and a high packing fraction result in increased fluidity. The ratio of the contribution made by the packing fraction to this improvement in fluidity to that of shape ranged from 1:1 to about 1:2.
\end{abstract}

\section{Introduction}

Limestone powder is very useful for the production of self-compacting concrete and high strength cement (Ouchi et al. 2008; Uchikawa 1994). Many investigators have studied the effect of limestone powder on the fluidity and the compressive strength of mortar and concrete. Applications of micro filler limestone powder or nano-sized $\mathrm{CaCO}_{3}$ to concrete have been also investigated (Nehdi et al. 1996; Sato and Beaudoin 2007). The Technical Committee on Limestone Powder Application at the Japan Concrete Institute has proposed a quality standard for limestone powder and put out a manual for the application of limestone powder to concrete (JCI 1998; Daimon and Sakai 1993). However, there are still many uncertainties regarding the fluidity of concrete with limestone powders, their particle size distribution and the shape of particles at low-water-to-powder ratios.

Many researchers have been studying the fluidity mechanisms of mortar and cement paste (Hanehara and Yamada 2008; Miyake and Matsushita 2007). Pursuing an interest in the fluidity of concentrated suspensions, the authors previously proposed a model for the formation of clusters (Sakai et al. 1997). This work revealed that when water in a suspension is confined by agglomeration, it

\footnotetext{
${ }^{1}$ Department of Metallurgy and Ceramics Science, Graduate School of Engineering, Tokyo Institute of Technology, Tokyo, Japan.

E-mail:esakai@ceram.titech.ac.jp

${ }^{2}$ Material Development Dept., Product Development

Div., Taiyo Yuden Co., Ltd., Gunma, Japan.
}

can be considered as being present in two forms, retention water and free water. In our previous model for concentrated suspensions (Sakai et al. 1997), though particles are dispersed by superplasticizer, individual particles may not be completely separated from each other but may form loosely associated clusters. Each cluster is made of aggregated particles. The retention water associated with the particles clusters is believed to have a significant effect on the fluidity of concentrated suspension. The fluidity of the suspension is governed by the retention water and, as the packing fraction of the aggregate particles is improved, the amount of retention water decreases and that of free water increases, resulting in enhanced fluidity. It has been reported that the packing fraction of particles and the shape of particles is influenced by the fluidity of cement and concrete (Uchikawa et al. 1989, Johansen and Andersen 1991). The authors also reported that for a given particle size distribution, the shape of the powder particles is one of the main factors that improve the fluidity of the paste (Sakai et al. 1997). The circularity of limestone powder is greater than that of fly ash containing unburned carbon and $\alpha$-quartz as impurities or ground blast furnace slag or Portland cement. Through the use of limestone powder, the fluidity of the paste is improved compared with the other cases. The influence of the circularity of powders on the fluidity of the paste consists of the packing and ball bearing effect of powders (Sakai et al. 1997). At the same time, the authors confirmed the earlier proposal that the packing density of particles improves in multimodal suspensions. Further, the authors revealed that when DSP cement (cement densified with small particles) (Bach 1978) having a low water-to-powder (w/p) 
Table 1 Chemical composition of LHC (mass\%).

\begin{tabular}{|cccccccccc|}
\hline Ig.loss & $\mathrm{SiO}_{2}$ & $\mathrm{Al}_{2} \mathrm{O}_{3}$ & $\mathrm{Fe}_{2} \mathrm{O}_{3}$ & $\mathrm{CaO}$ & $\mathrm{MgO}$ & $\mathrm{SO}_{3}$ & $\mathrm{Na}_{2} \mathrm{O}$ & $\mathrm{K}_{2} \mathrm{O}$ & $\mathrm{Cl}$ \\
\hline 0.14 & 26.55 & 2.63 & 3.06 & 63.45 & 0.74 & 2.50 & 0.18 & 0.34 & 0.003 \\
\hline
\end{tabular}

ratio was prepared into a bimodal suspension containing silica fume (an industrial byproduct containing ultra-fine particles) and cement, the fluidity of the DSP paste was affected greatly by the shape (i.e. the circularity) of the ultra-fine particles (Sakai et al. 2009).

However, there remain many questions with regard to the physical properties and the packing fraction of powders at low $\mathrm{w} / \mathrm{p}$ ratios as well as with regard to the fluidity of cement paste containing various types of powders. In addition, the availability of good quality silica fume has fallen recently, so it has become necessary to design other cement composites that include cement and ultra-fine particles that flow easily at low $\mathrm{w} / \mathrm{p}$ ratios. This paper describes the effects of the shape of limestone powder particles and packing fraction on the fluidity of suspensions at a low water-to-powder ratio for the development of new type high strength cement.

\section{Experiment}

\subsection{Materials used}

The cement used in the experiment was a low-heat Portland cement (LHC) with a density of $3.22 \mathrm{~g} / \mathrm{cm}^{3}$. Tables 1 and 2 list the chemical and mineral compositions of the LHC, respectively. As a dispersant, a polycarboxylic acid-based superplasticizer with polyethylene oxide graft chains of polymerization degree 34 (P-34) was used. The polymer of superplasticizer is $\alpha$-allyl- $\omega$-methoxypolyethylene-maleic anhydride copolymer with a graft chain of polyethylene oxide (Sakai et al. 2001).

Limestone powders with six different degrees of grinding were prepared using a ball mill (B) and a jet mill (J). In order of increasing degree of grinding, they were: $\mathrm{B} 1, \mathrm{~B} 2$, and $\mathrm{B} 3$ ground in the ball mill, and $\mathrm{J} 1, \mathrm{~J} 2$, and $\mathrm{J} 3$ ground in the jet mill. The jet mill used for the experiment pulverizes powders by self-impact. Uniform high-speed air flow in the vessel was ensured by installing many nozzles, as shown in Fig. 1.

\subsection{Test method}

\section{(1) Preparation and fluidity of paste}

The replacement ratios of LHC with limestone powder were $0,10,20$, and 30 mass $\%$, while the water-to-powder $(\mathrm{w} / \mathrm{p})$ ratios by mass were $0.30,0.275,0.250$, and 0.225 . As mixing water, a solution containing superplasticizer was prepared in such a manner that the solid content of P34 was $0.12 w t \%$ by mass of powder. As more superplasticizer was added, the apparent viscosity decreased to a minimum and then increased again. Because the minimum value was at a superplasticizer content of about $0.12 \%$ by mass in each case, the subsequent studies were carried out at a superplasticizer content of $0.12 \%$ by mass.
Table 2 Mineral composition of LHC (mass $\%$ ).

\begin{tabular}{|rrcc|}
\hline $\mathrm{C}_{3} \mathrm{~S}$ & $\mathrm{C}_{2} \mathrm{~S}$ & $\mathrm{C}_{3} \mathrm{~A}$ & $\mathrm{C}_{4} \mathrm{AF}$ \\
\hline 28 & 56 & 2 & 9 \\
\hline
\end{tabular}

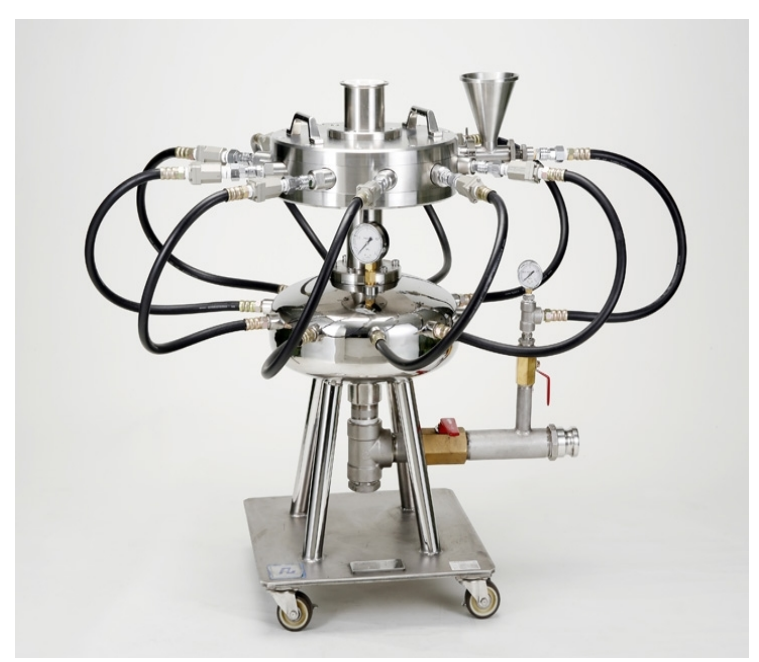

Fig.1 New-type jet mill.

Cement pastes were prepared by processing the LHC, the limestone powder, and the P34 solution in a revolution/rotation propeller-less blending system deforming conditioning mixer for one minute. With this mixer, the drum holding the materials spins (at $800 \mathrm{rpm}$ ) while its axis revolves in an orbit (at 2,000 rpm), thereby exerting an acceleration on the materials without the need for a mixing device such as a propeller. This type of mixer is suitable for mixing highly viscous suspensions at a low water-to-powder ratio.

The flow curve (i.e. the relationship between shear stress and shear rate) of the prepared pastes was obtained by adjusting the shear stress from $0.54 \mathrm{~Pa}$ up to $350 \mathrm{~Pa}$ and then back to $0.54 \mathrm{~Pa}$ (taking 6 minutes per cycle) using a double-cylindrical rotational viscometer of the stress-control type. The gap between the inner and outer cylinder in the coaxial-cylinder rotational type viscometer was $0.99 \mathrm{~mm}$, and the radius and the height of the inner cylinder were $20.71 \mathrm{~mm}$ and $55 \mathrm{~mm}$, respectively. The measurement temperature was $20^{\circ} \mathrm{C}$. Figure 2 shows an example of the flow curves for paste with J1 limestone powder. The replacement ratio of limestone powder to cement is 30 mass $\%$. The apparent viscosity of the pastes at a shear stress of $350 \mathrm{~Pa}$ was determined by the Bingham approximation of the rising section of the flow curve, as given by Equation (1). Measurements were taken at a temperature of $30^{\circ} \mathrm{C}$. 


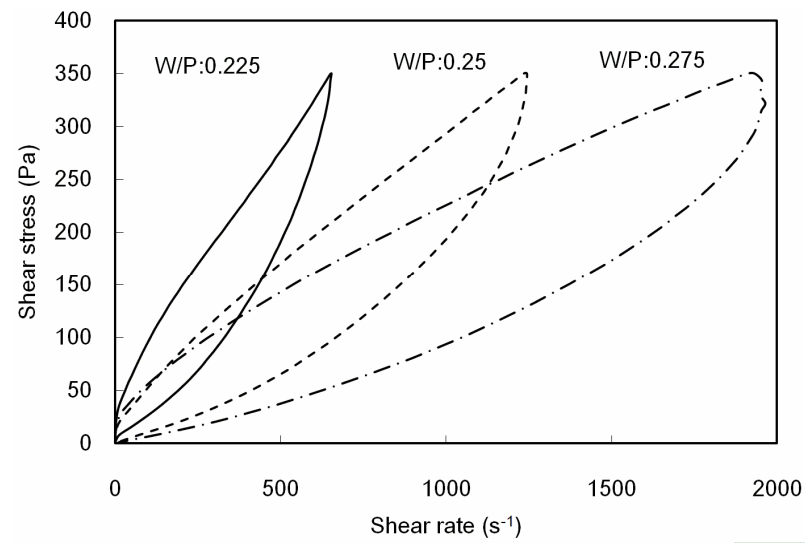

Fig.2 Flow curves of cement paste with $\mathrm{J} 1$ limestone powder.

$$
\tau=\tau_{\mathrm{o}}+\eta \dot{\gamma}
$$

where $\tau=$ shear stress, $\tau_{\mathrm{o}}=$ yield stress, $\eta=$ apparent viscosity and $\gamma=$ strain rate.

\section{(2) Characteristics of limestone powders}

The particle size distribution of the limestone powders was determined using a laser diffraction/scattering instrument for measuring particle size distributions. The average particle size of particles was also determined. Particle shape was evaluated by analyzing images of powder particles obtained with a scanning electron microscope (SEM) using an image analyzer and the point counting method (Sakai et al. 2009). From the SEM images of limestone powders, 300 to 1000 particles were extracted, and the surface area and peripheral length was measured using image software. From the obtained areas, the particle size distribution was obtained by approximation to spherical shapes. The shape of particles was evaluated in terms of their circularity, as given by Equation (2). While perfect circle has a circularity of 1.0, the circularity of practical spherical powder is less than 0.85 ; for example, the circularity of silica fume ranged from 0.73 to 0.82 (Sakai et al. 2009).

$$
\text { Circularity }=\frac{4 \pi(\text { projected area })}{\text { (perimeter of projected area })^{2}}
$$

\section{(3) Packing fraction of powders}

Conventionally, the Rosin-Rammler distribution as given by Equation (3) has been used to evaluate powder characteristics such as particle size distribution and packing fraction.

$$
D=100\left\{1-\exp \left(-D_{\mathrm{p}} / D_{\mathrm{e}}\right)^{\mathrm{n}}\right\}
$$

where $D=$ cumulative mass fraction of particles passing through each sieve $(\%), D_{\mathrm{p}}=$ particle size $(\mu \mathrm{m}), D_{\mathrm{e}}=$ particle size characteristic number $(\mu \mathrm{m})$ and $n=$ parameter describing the spread of particle sizes.

The $n$ value in the Rosin-Rammler distribution equation is presumed to have a relationship with the packing fraction of powder particles. However, the $\mathrm{n}$ value is unable to represent the complex shape of an actual particle size distribution; powders with different particle size distributions but close $\mathrm{n}$ values have similar packing fractions. For this reason, the authors formulated and then studied a new packing model capable of determining the packing ratio geometrically from the particle size distribution. Figure 3 is a flowchart outlining the packing simulation program written by the authors. This entailed incorporating a statistical component into the model proposed by Suzuki and Oshima (1983). The equation calculates the packing fraction by the following process:

- Two elements are selected randomly from the particle size distribution.

- The coordination number of each element is calculated. This value is the number of particles that can be arranged next to a given particle.

- The particle void fraction and virtual spheres are calculated geometrically from the volume fraction and particle size ratio of the elements.

- The summed partial void fraction is calculated for each element.

- The packing fraction is found from the void fraction.

\section{Results and discussions}

\subsection{Characteristics of limestone powders}

Figure 4 shows the particle size distributions of the powders used in the experiment. Overall, powders J1, J2, and $\mathrm{J} 3$ ground in the jet mill were finer than B1, B2 and $\mathrm{B} 3$ ground in the ball mill. Powders J2 and J3 had particle size distributions with a sharp peak at about $1 \mu \mathrm{m}$, whereas powders $\mathrm{J} 1, \mathrm{~B} 2$, and $\mathrm{B} 3$ had broad distributions with peaks ranging from $5 \mu \mathrm{m}$ to $10 \mu \mathrm{m}$. Table 3 lists the average particle size and circularity of the powder particles. The particle size distribution shown in Fig. $\mathbf{4}$ is a volume frequency distribution, from which a cumulative particle size distribution based on the number of particles was obtained; the average particle size was defined as the particle size at $50 \%$ of the cumulative particle size distribution. Figure 5 shows SEM photographs of LHC, B3 and $\mathrm{J} 3$. The circularity of the powder particles is listed in Table 3. The circularity of powders J1, J2, and J3 ground in the jet mill was higher than that of powders B1, B2, and $\mathrm{B} 3$ ground in the ball mill regardless of the degree of

Table 3 Average particle size and circularity of powders.

\begin{tabular}{|c|c|c|}
\hline Powder & $\begin{array}{c}\text { Average particle } \\
\text { size }(\mu \mathrm{m})\end{array}$ & $\begin{array}{c}\text { Degree of } \\
\text { circularity }\end{array}$ \\
\hline LHC & 16 & 0.67 \\
B1 & 16 & 0.65 \\
B2 & 2.6 & 0.66 \\
B3 & 2.0 & 0.72 \\
J1 & 3.4 & 0.74 \\
J2 & 1.6 & 0.74 \\
J3 & 0.8 & 0.76 \\
\hline
\end{tabular}




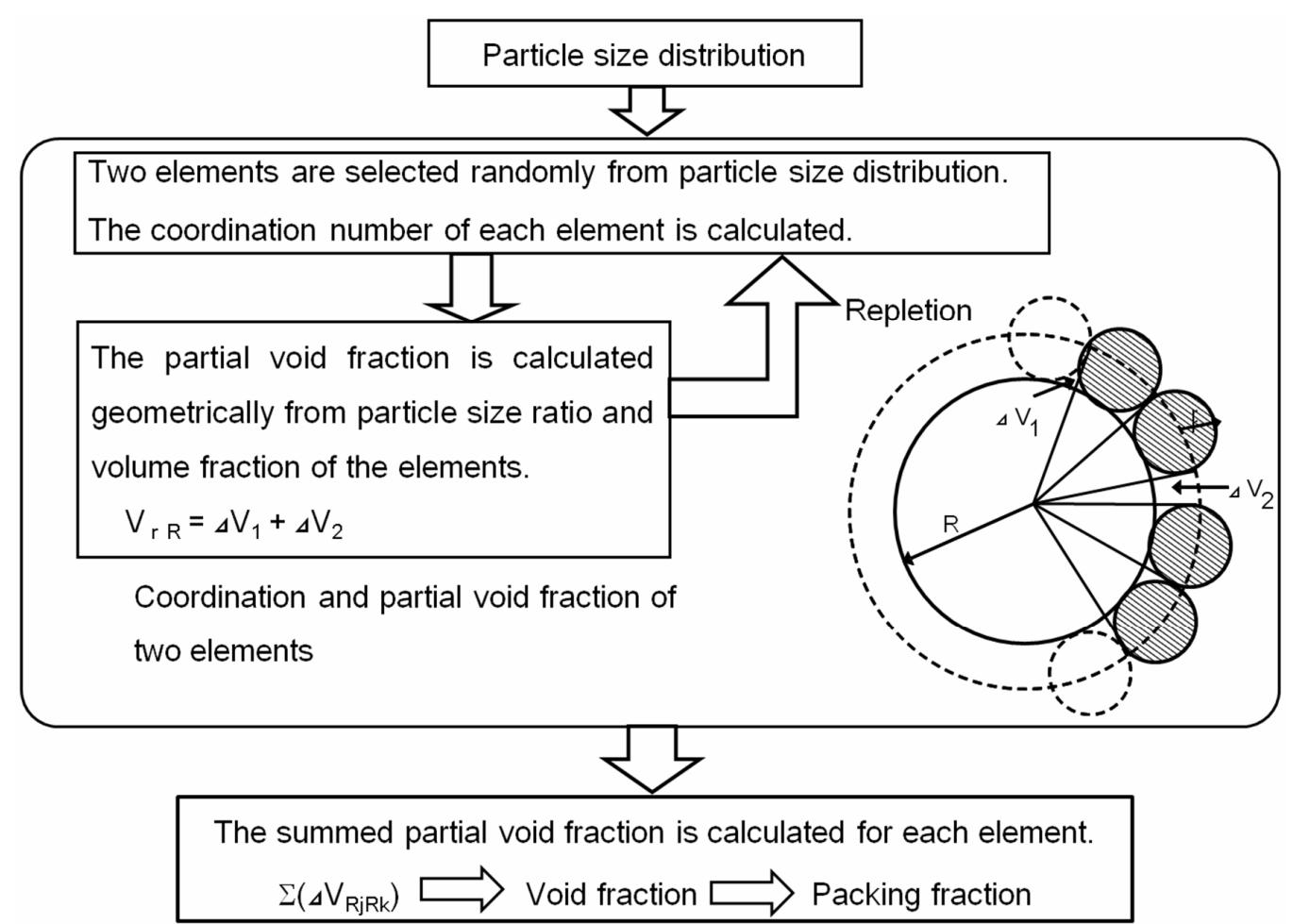

Fig.3 Flow chart of simulation for packing fraction of particles based on their particle size distributions.

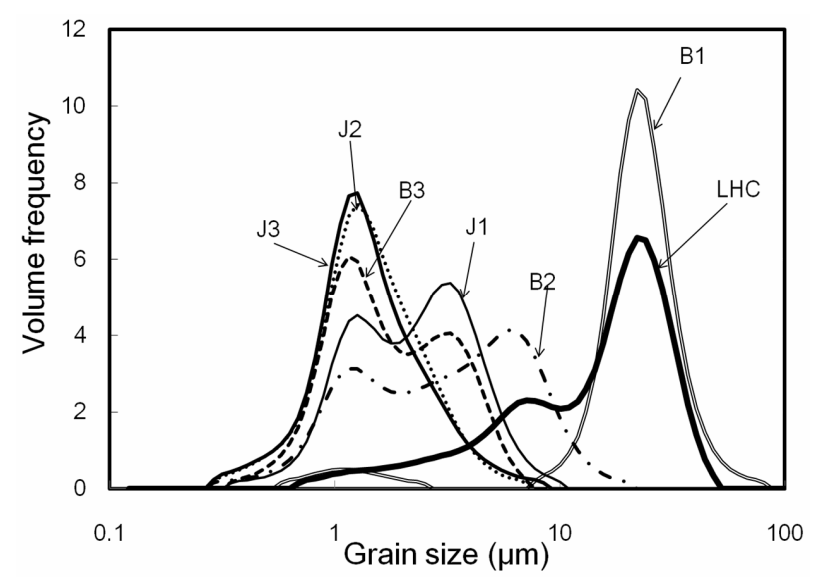

Fig. 4 Particle size distribution of limestone powders and LHC.

grinding. The limestone powders had a better shape than the LHC and the particles ground in the jet mill had a better shape than those ground in the ball mill.

\subsection{Simulation of packing fraction}

Figure 6 shows the results of simulating the packing fraction with various replacement ratios of LHC with limestone powder, based on the powder particle size distributions in Fig. 4. The packing fraction increased with rising replacement ratio up to a maximum value when the replacement ratio was $10-30 \%$, decreasing thereafter at higher ratios. With the exception of the case where the LHC was replaced with powder B1, the packing fraction was higher when the LHC was replaced with limestone powders of smaller average particle size. The highest packing fraction was obtained when the LHC was replaced with powder $\mathrm{J} 3$, which has the smallest average particle size. This is because powder J3 has a particle size distribution with a sharp peak at about $1 \mu \mathrm{m}$, whereas $\mathrm{J} 1$ and B3 have broad distributions with peaks ranging from $5 \mu \mathrm{m}$ to $10 \mu \mathrm{m}$. This result agrees with the conventionally held view that a high packing fraction is obtained by particles having a multimodal particle size distribution. Powder B1 had a multimodal particle size distribution. The packing fraction increased as the ratio of replacement with B1 increased until it approached that of $\mathrm{B} 1$ alone. Although the maximum packing ratio was at a replacement ratio of $10 \%$, taking powder $\mathrm{J} 3$ as an example, the packing fractions at replacement ratios of $10 \%$ and $30 \%$ were 0.78 and 0.77 , respectively. That is, the difference in packing fraction over this range of replacement was small. Accordingly, subsequent experiments were carried out at a replacement ratio of $30 \%$, where differences were observed relatively commonly, so that the characteristics of powders could be evaluated clearly.

\subsection{Adsorption of superplasticizer}

Figure 7 shows the amount of the superplasticizer adsorbed in the pastes at a water-to-powder (w/p) ratio of 0.3 and a superplasticizer content of $0.12 \%$ by mass when the replacement ratio of LHC with limestone powder was changed from $0 \%$ through $10 \%$ and $20 \%$ to $30 \%$. These values were calculated from the concentration of superplasticizer in the initial solution and the liquid phase (after superplasticizer adsorption), which was obtained by centrifugal separation of the suspension. 


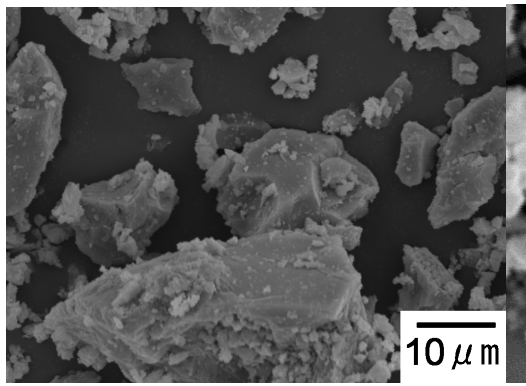

(a) LHC

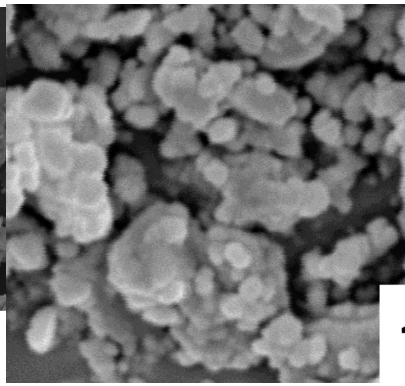

(b)B3

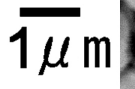

Fig. 5 SEM photographs of particles.

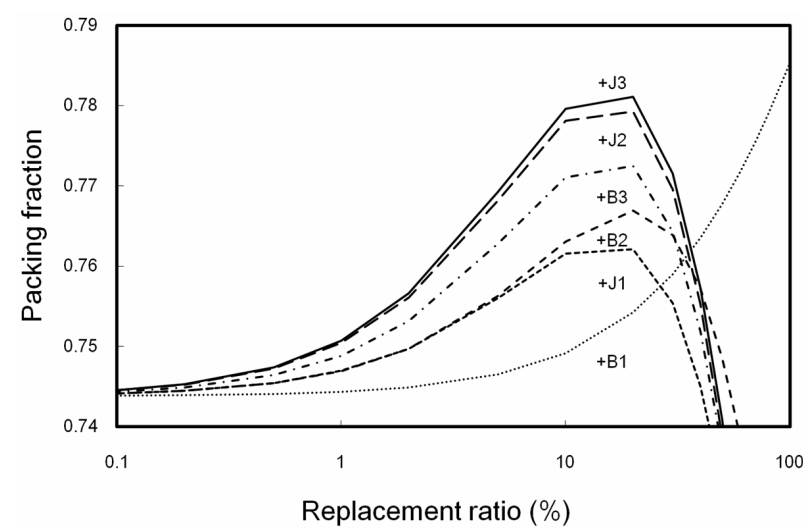

Fig. 6 Packing fraction of LHC with limestone powders.

The unadsorbed superplasticizer concentration was measured by carbon analysis using a Total Organic Carbon Analyzer (TOC). The quantity of superplasticizer adsorbed in pastes with limestone powder replacement was greater than that adsorbed in the LHC alone. The reason for this is that the LHC was replaced with limestone powder having a larger specific surface area than the LHC, with the exception of the case where the LHC was replaced with powder B1. However, even in the case where $30 \%$ of the LHC was replaced with limestone powder B3 (i.e. the case exhibiting the greatest superplasticizer adsorption at a superplasticizer content of about $0.12 \%$ ), the proportion of plasticizer remaining in the liquid phase was $53.6 \%$. That is, plenty of superplasticizer remained in the liquid phase and adsorption can be considered saturated. As a result of this finding, it was judged unnecessary in this study to take into consideration the effect of the adsorption of superplasticizer.

\subsection{Effects of limestone powder on fluidity of cement pastes}

Figure 8 shows the apparent viscosity of cement pastes when the w/p ratio was changed by replacing the LHC with limestone powder of the six different types. As the $\mathrm{w} / \mathrm{p}$ ratio decreased, the apparent viscosity increased (i.e. the fluidity decreased). The apparent viscosity at the same $\mathrm{w} / \mathrm{p}$ ratio varied greatly depending on the type of limestone powder added to the paste. The fluidity of LHC paste with B1 was not improved. The w/p ratio at which fluidity comparable to that of the LHC alone with a w/p ratio of 0.3 was obtained was 0.275 and about 0.25 ,

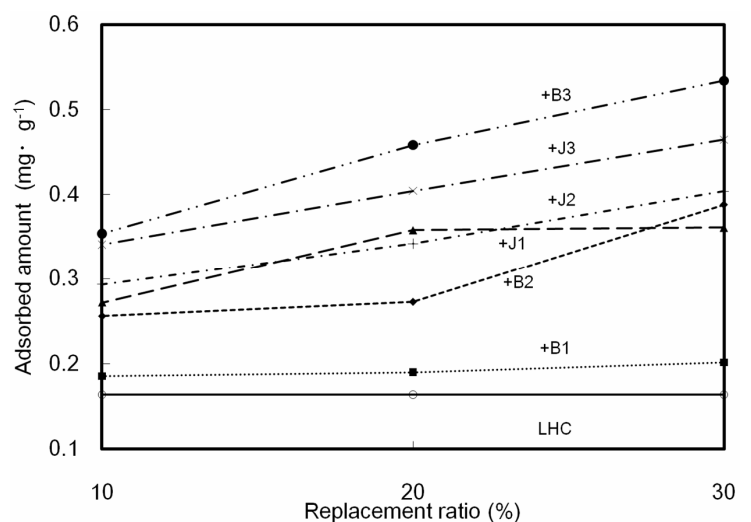

Fig. 7 Adsorption of superplasticizer.

respectively, for LHC replaced with powder B2 and with the other types of limestone powder. When the LHC was replaced with powders $\mathrm{J} 2$ or $\mathrm{J} 3$, an apparent viscosity of pastes at a w/p ratio of 0.225 is indicated, about the same value for that of the LHC alone with a w/p ratio of 0.3 .

Figure 9 shows the influence of the replacement ratio of limestone powder on the fluidity of pastes at a w/p ratio of 0.3 . At this $w / p$ ratio, the tendency is similar at replacement ratios of $10-30 \%$, with the exception of the case where LHC was replaced by powder B1. Figure 6 makes clear that the type of limestone powder has a more apparent effect at smaller $w / p$ ratios. When $\mathrm{LHC}$ was replaced by powders $\mathrm{J} 1, \mathrm{~J} 2$, and $\mathrm{J} 3$, which were ground in the jet mill, the paste had greater fluidity than when

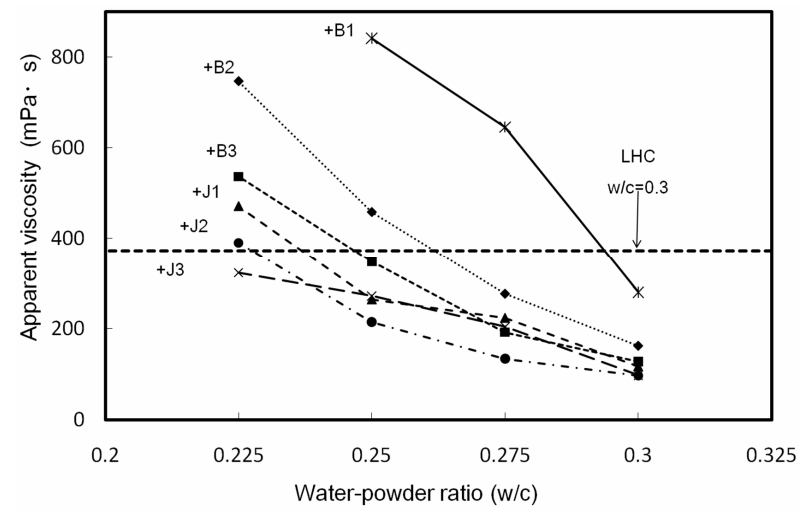

Fig. 8 Influence of water to powder ratio on fluidity of paste with various types of limestone powders (replacement ratio of limestone powder: 30 mass $\%)$. 


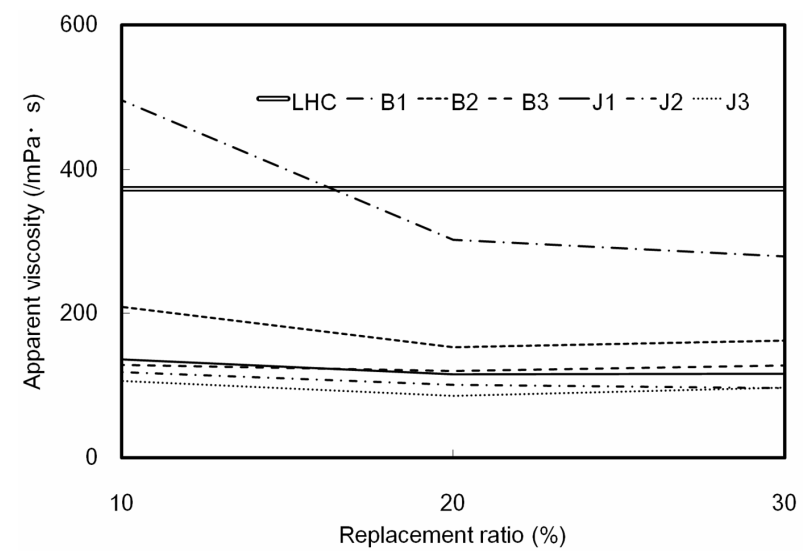

Fig. 9 Relation between replacement ratio of limestone powder and fluidity of paste (water to powder ratio:0.3).

powders B1, B2, and B3, which were ground in the ball mill, were used. Further, the fluidity improving effect tended to increase as the degree of grinding increased.

\subsection{Packing fraction of powders and fluidity of pastes}

In the case where the LHC was replaced by powder B1, the packing fraction was improved little and there was also no improvement in fluidity. Further, at low w/p ratios, paste fluidity improved more as the LHC was replaced with limestone powders with higher packing fraction. With replacement ratios of $10-30 \%$, there was no great difference in the packing fraction and fluidity showed a similar tendency. However, powders B2 and B3 exhibited a greater packing fraction than J1, though $\mathrm{J} 1$ improved fluidity more than B2 and B3. Accordingly, it became necessary to evaluate characteristics other than the packing fraction of powders in evaluating cement paste fluidity. The authors therefore decided to analyze cement paste fluidity taking into account both the packing fraction and the shape of the powder particles.

\subsection{Effects of packing fraction and powder par- ticle shape}

A multiple regression analysis was carried out, taking cement paste fluidity as an objective variable and the packing fraction and powder particle shape as an explaining variable. For this analysis, a w/p ratio of 0.3 and a superplasticizer content of about $0.12 \%$ by mass were used. The apparent viscosity, average circularity, and packing fraction of cement pastes with limestone powder replacement ratios of $0 \%, 10 \%, 20 \%$, and $30 \%$ were used. These values are listed in Table 4. The fluidity of paste is the inverse of the apparent viscosity of paste. The void fraction was calculated from the difference of the packing fraction of a certain powder and the packing fraction (1.0) when completely filling it. The degree of

Table 4 Analysis of multiple correlation.

\begin{tabular}{|c|c|c|c|c|}
\hline Powders & $\begin{array}{l}\text { Replacement } \\
\text { ratio (mass\%) }\end{array}$ & $\begin{array}{l}\text { Void } \\
\text { fraction }\end{array}$ & $\begin{array}{c}\text { Degree of } \\
\text { non-circularity }\end{array}$ & $\begin{array}{l}\text { Fluidity } \\
(\mathrm{mPa} \cdot \mathrm{s})^{-1}\end{array}$ \\
\hline \multirow{3}{*}{ B1 } & 10 & 0.251 & 1.504 & 2017 \\
\hline & 20 & 0.246 & 1.507 & 3301 \\
\hline & 30 & 0.241 & 1.511 & 3572 \\
\hline \multirow{3}{*}{ B2 } & 10 & 0.237 & 1.501 & 4778 \\
\hline & 20 & 0.233 & 1.502 & 6525 \\
\hline & 30 & 0.236 & 1.502 & 6162 \\
\hline \multirow{3}{*}{ B3 } & 10 & 0.229 & 1.490 & 7773 \\
\hline & 20 & 0.228 & 1.479 & 8313 \\
\hline & 30 & 0.238 & 1.468 & 7828 \\
\hline \multirow{3}{*}{$\mathrm{J} 1$} & 10 & 0.238 & 1.483 & 7339 \\
\hline & 20 & 0.238 & 1.466 & 8644 \\
\hline & 30 & 0.245 & 1.450 & 8573 \\
\hline \multirow{3}{*}{$\mathrm{J} 2$} & 10 & 0.222 & 1.484 & 8419 \\
\hline & 20 & 0.221 & 1.468 & 9909 \\
\hline & 30 & 0.230 & 1.453 & 10340 \\
\hline \multirow{3}{*}{$\mathrm{J} 3$} & 10 & 0.220 & 1.480 & 9372 \\
\hline & 20 & 0.219 & 1.459 & 11612 \\
\hline & 30 & 0.228 & 1.439 & 10248 \\
\hline $\begin{array}{l}\text { No add. } \\
\text { (LHC) }\end{array}$ & 0 & 0.256 & 1.500 & 2681 \\
\hline
\end{tabular}

(Void fraction: 1-Packing fraction, Degree of non-circularity:1/Degree of circularity, Fluidity:1/Apparent viscosity) 


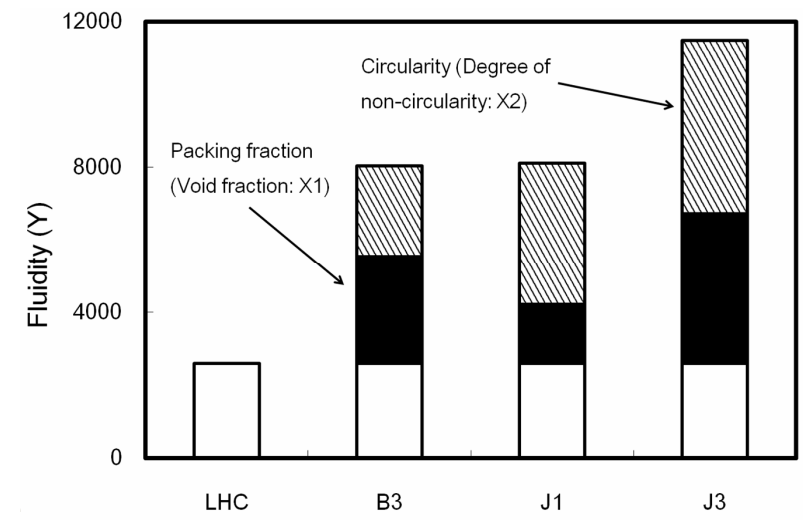

Fig. 10 Influence of packing fraction and circularity of powders on fluidity of paste.

non-circularity of powder is the inverse of the circularity degree of powder. Equation (4) below was derived from this multiple regression analysis.

$$
\begin{aligned}
& Y=-147513 X_{1}-77961\left(X_{2}-1\right)+79339 \\
& \left(\mathrm{R}^{2}=0.96\right)
\end{aligned}
$$

where $\mathrm{Y}=$ fluidity $=\left(10^{6} /\right.$ apparent viscosity $)(\mathrm{mPa} \cdot \mathrm{s})^{-1}$, $X_{1}=$ pore volume $=(1-$ packing fraction $), X_{2}=$ non-circularity $=(1 /$ circularity $), R=$ multiple correlation coefficient

The results of the analysis revealed that the fluidity could be approximated with accuracy by using the void ratio and non-circularity and that the packing ratio and circularity had large effects on the fluidity.

The contributions of particle packing fraction and shape to the improvement in fluidity when the LHC was replaced with powders $\mathrm{B} 3, \mathrm{~J} 1$, and $\mathrm{J} 3$ at a replacement ratio of $30 \%$ were determined from Equation (4) and are shown in Fig. 10, with the LHC at a w/p ratio of 0.3 taken as a benchmark. These contributions of the packing fraction and shape to fluidity improvement are represented in a visible form in the figure, which clearly shows that while B3 and J1 exhibit the same level of fluidity, the ratio of the contribution of the shape of the B3 ground in the ball mill to the improvement in fluidity to that of the packing factor is about $1: 1$, whereas the ratio for the $\mathrm{J} 1$ ground in the jet mill is about $2: 1$. The reason for this difference is that $\mathrm{B} 3$, with an average particle size of $2.0 \mu \mathrm{m}$, is finer than $\mathrm{J} 1$, which has an average particle size of $3.4 \mu \mathrm{m}$, while the change in the void ratio was 0.02 when powder B3 was used and 0.011 in the case of J1. That is, B3 contributed more to the change in fluidity. Powder J1 has a lower circularity than LHC and B3, so the contribution of the shape of powder $\mathrm{J} 1$ to the improvement in fluidity was greater than that of the B3 powder. Powder J3, with fine particles of good shape, made a large contribution to the fluidity.

Equation (5) was derived from the multiple regression analysis at a $\mathrm{w} / \mathrm{p}$ ratio of 0.225 .

$$
\begin{aligned}
& Y=-42259 X_{1}-22690\left(X_{2}-1\right)+22625 \\
& R^{2}=0.97
\end{aligned}
$$

As these results demonstrate, it is necessary to take into account both the packing fraction and shape when evaluating fluidity improvement.

\section{Conclusions}

The authors studied the effects of powder packing fraction and shape on the fluidity of suspensions containing low-heat Portland cement and limestone powders ground under different grinding conditions at low water-to-powder ratios. The following conclusions are drawn from the study.

(1) The addition of finely ground limestone powders prepared by jet mill increased the fluidity of suspensions. When the LHC was replaced with powders $\mathrm{J} 2$ or $\mathrm{J} 3$, an apparent viscosity of pastes at a w/p ratio of 0.225 is indicated, about the same value for that of the LHC alone with a w/p ratio of 0.3 .

(2) A simulation was used to obtain the packing fraction of particles directly from the particle size distribution and the results were used in the analysis of fluidity. The fluidity of a suspension could be approximated with accuracy using the packing fraction determined from these calculations and the circularity as determined from SEM photographs.

(3) The shape of particles and the particle size distribution both affected fluidity. Particles with a circular shape and a high packing fraction result in increased fluidity. The ratio of the contribution made by packing density to this improvement in fluidity to that of shape ranged from $1: 1$ to about $1: 2$ in this study.

\section{Acknowledgments}

The authors wish to thank Mr. Ryoichi Miyakawa, President of Aishin Corp, and Mr. Nobuo Tsukihara, General Manager of Aishin Nano Technology, for providing the limestone powders ground in the jet mill. Thanks also go to Taiheiyo Cement Corp. for providing the limestone powders ground in the ball mill.

\section{References}

Bache, H. H. (Densit A/S) (1978). "Cementitious composite materials." Japanese published examined application 60-59182 (WO80/00959) (Claimed priority 1978).

Daimon, M. and Sakai, E. (1993). "Limestone powder concerning reaction and rheology." Proc. $4^{\text {th }}$ CANMET/ACI/JCI Int. Conf. on Recent Advances in Concrete Tech., Shigeyoshi Nagataki Symp. on vision of Concrete $21^{\text {st }}$ century, 41-54.

Hanehara, S. and Yamada, K. (2008). "Rheology and early age of cement system." Cement \& Concrete Research, 38(2), 175-195.

Japan Concrete Institute (1998). Technical Committee 
Report on Limestone Powder Application. (in Japanese)

Johansen, V. and Andersen P. J. (1991). "Particle packing and concrete properties." Materials Science of Concrete II, edited by Skalny, J. and Mindess, S., The American Ceramics Society, 111-147.

Nehdi, M., Mindess, S. and Aitcïn, P. C. (1996). "Optimization of high strength limestone filler cement mortars." Cement \& Concrete Research, 26(6), 883-893.

Ouchi, M., Sakai, E., Sugiyama, T., Mitsui, K., Shindo., T., Maekawa., K. and Noguchi, T. (2008). "Self-compacting concrete in Japan." Proc. $8^{\text {th }}$ Symp. Utilization of high-strength and high-performance concrete, Tokyo, Japan, 72-91.

Sakai, E., Kawakami, A. and Daimon, M. (2001). "Dispersion mechanisms of comb-type superplasticizers containing grafted poly (ethylene oxide) chains.” Macromol. Symp. 175, 367-376.

Sakai, E., Hoshino, S., Ohba, Y. and Daimon, M. (1997). "The fluidity of cement paste with various types of inorganic powders." Proc. $10^{\text {th }}$ Int'l Cong. Chemistry of Cement, Vol. 2, $2 \mathrm{ii} 02$ (8 pp.).

Sakai, E., Kakinuma, Y., Yamamoto, K. and Daimon, M. (2009). "Relation between the shape of silica fume and the fluidity of cement paste at low water to powder ratio." Journal of Advanced Concrete Technology, 7(1),
13-20.

Miyake, J. and Matsushita, H. (2007). "Evaluation method for consistencies of mortars with various mixture proportions." Journal of Advanced Concrete Technology, 5(1), 87-97.

Sato, T. and Beaudoin,, J. J. (2007). "The effect of nano-sized $\mathrm{CaCO}_{3}$ addition on the hydration of cement paste containing high volumes of fly ash." Proc. $12^{\text {th }}$ Int'l Congress On the Chemistry of. Cement, ST3, sustainable development and climate change initiatives.

Suzuki, M. and Oshima, T. (1983). "Estimation of the co-ordination number in a multi-component mixture of spheres." Powder Technology, 5, 159-166.

Uchikawa, H., Uchida, S. and Okamura, T. (1989). "Influence of fineness and particle size distribution of cement paste, mortar and concrete." CAJ Proceedings of Cement and Concrete, 43, 42-47. (in Japanese)

Uchikawa, H. (1994). "Characterization and material design of high-strength concrete with superior workability." Cement Technology (edited by Gartner, E.M. and Uchikawa, H.), 143-186.

Yahia, A., Tanimura, M. and Shimoyama, Y. (2005). "Rheological properties of highly flowable mortar containing limestone filler - Effect of powder content and W/C ratio." Cement \& Concrete Ressearch, 35(3), $532-539$ 